\title{
Occupational Therapy's Role in Recovery of Children with Mental Disabilities
}

\author{
Maria-ElenaOsiceanu ${ }^{1 *}$ and Ştefania Zaharescu ${ }^{2}$ \\ ${ }^{1}$ Technical University of Civil Engineering of Bucharest, Lacul Tei Bvd, no. 122-124, Bucharest, Romania \\ ${ }^{2}$ Special Secondary School no. 8, Bucharest, Romania
}

\begin{abstract}
This paper aims to identify ones of the most effective methods and procedures for improving self-esteem and reducing the frequency of aggressive behaviors recorded at the children with mental disabilities. The basic motivation of the work is in line with the widening of the concerns about the ways of harmonious developing the personality of the pupils from special primary schools, especially those with behavioral disorders. The working hypothesis from which we started was that if, in the framework of occupational therapies, we use as a teaching strategy melotherapy and body expression activities, then we can substantially improve the quality and efficiency of the process of shaping the image and the esteem and reduce behavioral disorders at the children with mental disabilities. The research was carried out on a number of 40 students with light and moderate mental disability (primary classes), with behavioral disturbances and psycho-behavioral immaturity. In conclusion, we can affirme that we have tried through this work to demonstrate the importance of Occupational Therapies (OT), performed through melotherapy and body expression activities, on the personality of deficient children, on the development of self-esteem, aesthetic taste, and some ways to achieve these activities.
\end{abstract}

Keywords: Ocupational therapy; Mental disability; The complex and integrated educational therapy; Melotherapy; Body expression; Selfesteem/ self-confidence; Behavioral disorders

\section{Introduction}

Specialist research reveals that the mental deficient lives in an almost totally destructed universe due to the lack of psychological equipment of the first childhood, requiring systematic education to resume and supplement its purchases, depending on the degree of physical development and intellectual, aptitude and educational influences to which he was subjected.

Occupational therapy (OT) has a leading role in organizing the instructive-educational-rehabilitation process for pupils with behavioral disorders in a primary school in special schools. Through the occupational therapy activities, pragmatic adaptation (learning professional, manual, intellectual), social adaptation (ways of interpersonal communication), aesthetic adaptation (body expression techniques), as well as educational adaptation can be made possible.

Through the occupational therapy activities conducted by teachereducator in complex and integrated educational therapy (CIET), the deficient child is involved in a gradual learning process that will address simple, pleasant, attractive activities and will acquire a rich (visual, perceptual, motric, aesthetic) experience of general understanding, activities that will at the same time fulfill the corrective role in terms of some socio-affective disorder.

In this context, the teacher has the freedom to choose the type of activity he/she performs, depending on the particularities of the class, the difficulties of pregnancy and the mental development of each child. Educational practice has confirmed that the heterogeneity of the forms of recovery in each class and with each pupil requires the organization of activities on groups with a similar level of development, the pupils receiving differential support from the teacher-educators. In addition, the degrees of difficulty of the tasks they have to execute must be unattached.

One important point to emphasize: in choosing a method of recovering, formation of and educating children with mental disabilities, it is necessary to take into account the preference of them, the pleasure and relaxation they produce so that their application may not trigger any anxiety, blockage, or opposition.

\section{Clarification of Key Terms}

\section{Definition of mental disability (MD)}

The concept of mental deficiency remains extremely complex and often confusing or even contradictory. When we speak about the mental deficiency, not only the sphere of conceptual definitions is different from one author to another, from one area of activity to another (psychiatry, psychology, pedagogy, social security etc.), but also the terminology in which synonymy such as handicap, deficiency, disability does not bother as much as the terms that cause confusion (backwardness, delay, failure, weakness) and can induce the idea of a possible return to normal [1]. Currently, terms such as "handicap" and "handicapped" is recommended to be replaced by "disability" and "person with disability" in order to protect human dignity [2].

The traditional concept of a person with mental deficiency refers to its reduced possibilities to act, compared to a healthy person. The term "mental deficiency" is used as a notion to identify deficiencies, loopholes, insufficiencies, morphological or functional disfunctions existing in an individual. Mental deficiency is a global deficiency that concerns the individual's entire personality: structure, organization, intellectual development, affective, psychomotor, behavioral-adaptive.

*Corresponding author: Osiceanu ME, Technical University of Civil Engineering of Bucharest, Lacul Tei Bvd, no. 122-124, Bucharest, Romania, Tel: + 40 720899024; E-mail: osiceanum@gmail.com

Received: September 15, 2017; Accepted: September 21, 2017; Published: September 28, 2017

Citation: Osiceanu ME, Zaharescu Ş (2017) Occupational Therapy's Role in Recovery of Children with Mental Disabillities. Clin Exp Psychol 3: 167. doi 10.4172/2471-2701.1000167

Copyright: @ 2017 Osiceanu ME, et al. This is an open-access article distributed under the terms of the Creative Commons Attribution License, which permits unrestricted use, distribution, and reproduction in any medium, provided the original author and source are credited. 
The defining note for the mental deficiency is the alteration of the biophysiological and psychological integrity, being, in fact, a differentiated form of personality organization [3]. The deficient child is one whose physical, innate or acquired physical abilities are clearly inferior to children of the same chronological age, a deficiency that cannot be totally removed but only recovered to a certain degree, compensated, improved, valued according to the real possibilities of the individual and the limited acquisition, retention, transfer capacity.

\section{Occupational therapy (OT)}

The meaning of the occupational therapy (OT) phrase derives from the words that comprise it: therapy (means the treatment of a disease, disability, etc.) and occupation (meaning the idea of engaging and participating effectively and motivated). Occupational therapy is primarily concerned with ensuring the health and well-being of the individual in their living environment, helping them develop their skills to meet their personal needs and respond to the demands of the environment. Occupational therapy can be used effectively to alleviate the disfunctions of the human body, thus contributing to increasing the individual's adaptation to society.

Within the Occupational Therapy Practice Framework: Domain and Process, OT is defined: "as the therapeutic use of everyday life activities (occupations) with individuals or groups for the purpose of enhancing or enabling participation in roles, habits, and routines in home, school, workplace, community, and other settings. Occupational therapy practitioners use their knowledge of the transactional relationship among the persons, his or her engagement in valuable occupations, and the context to design occupation-based intervention plans that facilitate change or growth in client factors (body functions, body structures, values, beliefs, and spirituality) and skills (motor, process, and social interaction) needed for successful participation. Occupational therapy practitioners are concerned with the ending result of participation and thus enable engagement through adaptations and modifications to the environment or objects within the environment when needed. Occupational therapy services are provided for habilitation, rehabilitation, and promotion of health and wellness for clients with disability and non-disability related needs". (adapted from AOTA, 2014, p. 2).

The Integrated Learning Educational Therapy (ILET) program for special schools is of particular importance to occupational therapy. By their content, these activities predominantly refer to the area of personal and social development aiming at the independence of the child with $\mathrm{MD}$, as well as its integration into a constantly changing environment.

Recovery through occupational therapy is successfully applied in all forms of mental deficiency.

For the children with mental disabilities, the benefits of OT are to provide activities that stimulate the systems responsible for the dysfunctions and to improve the deficits that were identified during the initial assessment. Improvements may occur in any of the following areas: concentration; gross and/or fine motor coordination and motor planning; independence in self-care skills; self-confidence; self-esteem; speech and language (both expressive and receptive); behaviour, including tactile defensiveness; academic performance; cooperation with siblings and parents [4].

Ooccupational therapy intervention for children with mental disability is also an ongoing process that is both gradual and dynamic. The intervention often requires repeated drills and practice to achieve internalization and learning, and performance in a variety of contexts to enable generalization. This enables and encourages the pupil's participation in the many contexts of his/her life [5]

Occupational therapy is the art and science of directing the child's participation with ESCs to accomplish certain tasks in order to restore, support and enhance performance, facilitate the learning of skills and essential functions for adaptation to the social environment. Verza [6] showed that the most significant occupational therapies for children with MD are: ludotherapy, melotherapy, dance therapy and ergotherapy.

\section{Melotherapy and psychotherapy for body expression - complex means of recovering the child with mental disability}

The current program for the recovery of deficient children from special schools in Romania attaches great importance to occupational therapy and psychotherapy. Expression activities include art therapy, which refers to the use of means of artistic expressions for therapeutic purposes. These means prove their effectiveness in that they appeal to affectivity, in order to achieve an optimal relationship between the educator and the pupil [7].

Melotherapy falls into the vast area of occupational therapy and expression psychotherapy. From the point of view of the activities required for children, melotherapy can be divided into two forms: active (instrumental or vocal music) and receptive (musical auditions).

Educational music therapy uses the following types and forms of organizing and conducting musical activities: song, musical games, musical games - exercise, text and song games and musical auditions [8].

The therapeutic value of music stems from the many influences it has on the human psyche due to the complexity of the musical phenomenon itself. In mentally disabled children, music is used to recover their decompensated personality, and to establish another type of communication, different from the verbal one. Many children with mental disabilities are known to have a lively interest in music, dance, painting, playing, making objects, etc., activities that are not only energy-consuming moments, but also opportunities to develop motor skills. In students who experience emotional instability, the use of melotherapy, reduces mental tension and aggression, improves cooperation within the group and teamwork.

Murphy has shown that melotherapy also helps children with relational disorders because it favors spontaneous participation in group activities. In special schools, it is useful to associate children in groups or to work individually, depending on the performances they are capable of in the field of music and according to their intellectual retardation level. In addition to disturbing relationships with the other, the MD with a child also has difficulty in dealing with his or her own body, labeled as a bodily disorder, included in the wider framework of recognizing and identifying the "Self".

Melotherapy and psychotherapy of body expression, as elements integrated in the instructional-educational approach, suppose a good knowledge of the child by the educator. He must anticipate the concrete interpretation of the act of expression, which involves the expression of each child according to his / her own personality. Knowing and following a particular therapeutic plan is the task of each teachereducator and of the entire team of specialists.

To achieve success, the teacher-educator will create a special climate, will have a benevolent attitude and behavior and will intervene whenever it will be needed to remove any blockages and anxiety. Another mandatory moment in melotherapy and body expression 
therapy is the selection of those artistic pieces that cause strong emotional experiences that mobilize and train the entire personality of the student. Moving from practical activity to the acquisition of a song, dance or choreographic figures - backed by the complexity of rhythmic gymnastics - is the most important part of the therapeutic act. Here comes the mastery of the teacher educator, who in each sequence creates a stable unit in the whole artistic act, applying the principle of small steps as well consolidated and welded teaching units.

Combining the elements of occupational therapy with games of skill and exercise, rhythmic dance, popular games, all accompanied by appropriate songs, obviously raises the quality of the therapeutic act and the whole instructive-educational process.

From one class to another, from one child to another, tasks can become more complex - in relation to artistic skills and inclinations, stimulating the individuality of the student, his/her integration into the collective, the learning effort, the observance of discipline rules schooling - finally achieving progress in recovery and integration.

The pupil's activity in occupational therapy activities increases his/ her independence and increases the social insertion, thus preparing him/her for confronting the exigencies of life. Throughout the act of learning and execution, the child gains self-confidence, develops his will and affection, becomes a participant in his own perfection, his entire personality is mobilized, thus facilitating the integration process both in the classroom and in the social environment [9-13].

\section{Research Design}

\section{Purpose of research}

Increasing self-esteem, self-confidence, compensation and amelioration of behavioral disorders of mentally disabled students through occupational therapy activities based on modern, non-formal melotherapy and body expression methods and techniques.

\section{Objectives of research. In the present research the following objectives were targeted}

\section{Objectives on short term:}

1. Deepening students' knowledge by investigating different aspects of emotional development;

2. Analysis of the initial level of development of self-esteem and self-confidence of investigated subjects;

3. Inventory of educational factors with a major role in the development of socio-emotional abilities of primary school children.

\section{Objectives on long term}

1. Applying a recovery and training program in occupational therapy activities using melotherapy and body expression activities to increase well-being in the educational environment, thereby contributing to diminishing emotional problems in children with ESL in the primary cycle;

2. Highlighting the effects of the recuperatory-formative program of melotherapy and body expression (music, motion and dance) developed within occupational therapy activities centered on improving self-image, increasing self-esteem and trust in yourself forces, and reducing disorder behavior in students with mental disabilities.

\section{Research hypotheses}

Basic assumptions of the research were: $\mathrm{H} 1$ : We assume interdependent relationships between emotional development (the frequency and suitability of affective manifestations, emotional vocabulary, sentiment recognition) and socio-relational behavior (aggressiveness-docility).

H2: If we use the therapies and body expression activities as a teaching strategy in occupational therapy activities, then we can substantially improve the quality and efficiency of the formation and modeling of self image and self-esteem and reduce behavioral disorders in children with mental disability.

\section{Research group}

In order to pursue the objectives and verify the hypotheses formulated, 40 students from the Special Secondary School no. 8 Bucharest, of which 26 boys and 14 girls aged between 7 and 12 years. They were divided into two equal lots of 20 students, as follows:

1. The first batch (the experimental group) - participating in the melotherapy and body expression rehabilitation program developed within occupational therapy activities - consists of 20 students: 13 boys and 7 girls.

2. The second batch (control group), consisting of 20 students, 11 girls and 9 boys, who followed a regular program in complex and integrated educational therapy (CIET) activities.

Both groups of subjects were relatively balanced in terms of age and degree of deficiency as can be seen in the following graphs (Figure 1).

Note: Both the subjects in the experimental group and the control group, have light or moderate mental disabilities and other associated disorders (in particular, behavioral disorders, psycho-behavioral immaturity, socio-relational disorders, attention deficit hyperkinetic disorder - ADHD, oppositional disorder, language disorders, etc.). The selection of the students from the two groups was made after consulting the medical and social file of each of them (in the special school, each student has such a file, based on which admission to this kind of school is made). Besides the analysis of the documents, which was the first step in the development of the research groups, it should not be forgotten that the teacher-educator in the special school classes knows very well the evolution and the psychoindividual particularities of each child, which he pursues during a few years. In the composition of the samples, consideration was given to a relative degree of balance/homogeneity, in terms of age and degree of deficiency. What makes the difference between the two batches, is that the students in the research group participate in a recovery and training program through occupational therapy activities (melotherapy and body expression activities), while those in the control group, do not (Figure 2).

\section{Research methods}

The initial research was carried out within the Special Secondary School no.8 - Bucharest, in the school year 2016 - 2017, divided into three stages, as follows:

- First stage (ascertaining): September - October 2016

- Acquiring data about the subjects of the two batches;

- Testing and questioning the 40 subjects;

- Interpretation of results on applied samples.

- Second stage (experimental-ameliorative): November 2016 - April 2017

- Elaboration and application of the rehabilitation and training 


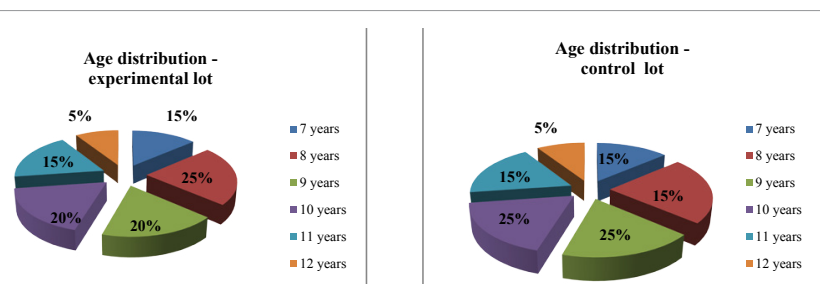

Figure 1: Structure of the lot according to the age of subjects.
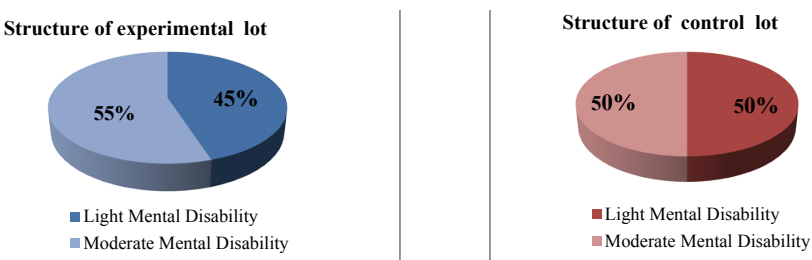

Figure 2: Structure of the lot according to the degree of mental disability.

program by melotherapy and body expression, initiated and performed differentially (depending on the psychoindividual particularities of each subject in the experimental group), within the activities of the OT.

- Third stage (analysis and interpretation of the results from the experimental phase): May - June 2017

- Applying the tests and questionnaires in the final evaluation;

- Interpretation of results in final testing and comparative analysis of the two batches;

- Final conclusions for confirming / invalidating research hypotheses.

The methods and tests applied in each of these three stages of the research were chosen in order to obtain the necessary information for the knowledge of the subjects in three fundamental directions, namely:

I. To analyze the initial level of development of self-esteem and self-confidence, components of self-image. Between September and October 2016 we realized:

- Studying school documents, personal documents and students' anamnesis;

- Individual conversations with teachers and students' families;

- Investigation (used to obtain meaningful information about: integrating college students, difficulties encountered in the socioschool environment, level of self-esteem, self-confidence);

- Applying questionnaires and tests (questionnaire for determining the "Profile of the Child in Extremes" - intended for teachers to assess indirectly the individual characteristics of pupils - the first seven items of the questionnaire evaluate the attitude towards one's self and the attitude towards others and the last three, socio-affective behavior, test for emotional maturity investigation - adapted by Tereza M. Amabile);

- Systematic observation of students and monitoring of inappropriate behaviors;

- Assessing the peculiarities of developing the affective sphere, assessing self-esteem and self-confidence.

II. In order to improve self-esteem. Between October 2016 and April 2017, based on the analysis of the data and results obtained from the first stage, a set of activities of melotherapy and body expression (music, movement and dance) carried out within occupational therapy were applied. The purpose of this intervention program was to improve the process of image formation and self-esteem and reduce behavioral disorders in subjects in the experimental group by developing positive behaviors (e.g., formulating a request, waiting for the turn, verbal expression of anger, sharing toys, adherence to rules).

III. In order to appreciate the ultimate level of self-esteem and selfconfidence, as well as perceptual-motor structures. In order to make a comparative analysis of the pupils' development level as a result of participating in an intervention program with a recuperative and formative role, we reapplied the initial proofs (May 2017) during the final evaluation (Table 1).

\section{Recovery and training program for occupational therapy}

Socio-educational intervention is complex and with long-term objectives. It is very important for a teacher who work in a special school to be able to "read" the student correctly when doing a normal job.

Talking with teachers highlights the fact that they think it is much easier to work with a child able to express feelings, passions and pleasure to communicate, he is sincere in what he conveys to you his own in contradiction to the child who is afraid of socializing because, he is immature and labile affectionate.

Elements of affective immaturity, on the backround of mental deficiency, make it difficult to control aggressive impulses. Teachers believe that in these situations, parents are the ones who can make real contributions to educating his own children and that responsibilities need to be shared. Parents have the most information about their children and this information can be used to make decisions about their training. To increase the efficiency and effectiveness of the school, teachers recognize the importance of the family and seek to attract them into the teaching process.

The analysis of the results of the "Child's Profile in the Extreme" questionnaire confirmed that when students are supported by their parents and teachers, they can develop positive attitudes towards the educational environment and show desirable social and emotional behaviors.

Corroborating and interpreting the information obtained by applying all the methods presented in the previous part, has led to the need to develop a recuperative-formative program through non-formal methods and techniques that help to reduce behavioral disturbances and improve image and self-esteem, to increase confidence in itself, that is why we have designed an intervention program, developed within the framework of the occupational therapy activities, for the students in the experimental group.

The program was run for 6 months, 3 times a week. In this program were promoted occupational therapy activities realized by methods specific to melotherapy and dance. We chose melotherapy and dance because we noticed that in children with mental disabilities and those with hyperactivity (ADHD), this type of therapy can be used successfully both to improve voluntary inhibition and to achieve socioemotional performance.

Melotherapy is motivating and agreeable, it can encourage relationship, relaxation, learning and self-expression, and can also be used to establish contact with the child. In addition, it is an important way of expression. Through melotherapy, we try to sensitize the human being with music to facilitate the acquisitions and the progress in the cognitive and non-cognitive development. 
Citation: Osiceanu ME, Zaharescu Ş (2017) Occupational Therapy's Role in Recovery of Children with Mental Disabillities. Clin Exp Psychol 3: 167. doi: $10.4172 / 2471-2701.1000167$

Page 5 of 8

\begin{tabular}{|c|c|c|c|c|}
\hline Nr. Crt. & Name & Sex & Age & Diagnostic \\
\hline & B.C.F. & male & 7 years & L.M.D, primary enuresis \\
\hline & C.A. & male & 7 years & M.M.D; ADHD; opposition disorder \\
\hline & C.A.I. & female & 8 years & L.M.D; language disorder \\
\hline & D.M.N. & male & 7 years & M.M.D; ADHD \\
\hline & C.M. & female & 8 years & M.M.D \\
\hline & G.F. & male & 8 years & L.M.D; ADHD \\
\hline & B.M. & male & 8 years & L.M.D; language disorder \\
\hline & G.F.V. & female & 10 years & M.M.D \\
\hline & O.P.M. & male & 9 years & M.M.D; behavioral immaturity \\
\hline & P.C. & male & 8 years & L.M.D; epilepsy with partial and secondary generalized seizures \\
\hline & G.M. & female & 9 years & L.M.D; dyslexia; dysgraphia \\
\hline & I.A. & male & 9 years & L.M.D; opposition disorder \\
\hline & N.M. & male & 10 years & M.M.D; polymorphic dyslalia; ADHD \\
\hline & S.A. & female & 9 years & L.M.D; language disorder \\
\hline & B.A. & male & 10 years & M.M.D; attention deficit; sporadic primary enuresis \\
\hline & D.G. & male & 11years & M.M.D; polymorphic dyslalia \\
\hline & D.F. & female & 10 years & L.M.D; dysgraphia, dyslexia \\
\hline & G.L. & female & 12 years & L.M.D; behavioral immaturity \\
\hline & R.C. & male & 11 years & M.M.D; dyslalia; attention deficit \\
\hline & P.D. & male & 11 years & M.M.D; language disorder; behavioral disorders \\
\hline
\end{tabular}

Table 1: Nominal table with subjects of experimental lot.

\begin{tabular}{|c|c|c|c|c|}
\hline Nr. Crt. & Name & Sex & Age & Diagnostic \\
\hline & B.S.M. & female & 7 years & L.M.D \\
\hline & D.A. & male & 8 years & M.M.D \\
\hline & I. D.F & male & 7 years & M.M.D; psycho-behavioral and socioaffective immaturity \\
\hline & I.M. & female & 7 years & L.M.D; attention deficit \\
\hline & I.M.M. & male & 8 years & L.M.D; socioaffective immaturity \\
\hline & P.M. & male & 8 years & M.M.D; ADHD \\
\hline & A.A. & male & 9 years & L.M.D; psycho-behavioral immaturity \\
\hline & D.A. & female & 9 years & M.M.D \\
\hline & D.I. & female & 10 years & L.M.D; behavioral disorders \\
\hline & P.V. & female & 10 years & $\begin{array}{l}\text { M.M.D; language disorder; socioaffective immaturity; behavioral } \\
\text { disorders }\end{array}$ \\
\hline & D.V. & male & 9 years & L.M.D; socioaffective immaturity; behavioral disorders \\
\hline & I.M. & male & 10 years & M.M.D \\
\hline & L.C. & female & 9 years & L.M.D; behavioral disorders \\
\hline & M.G. & male & 9 years & L.M.D \\
\hline & M.A. & female & 10 years & M.M.D; language disorder; behavioral disorders \\
\hline & O.M. & female & 10 years & M.M.D; attention deficit; sporadic primary enuresis \\
\hline & O.C. & male & 11 years & L.M.D \\
\hline & P.M. & female & 12 years & M.M.D; polymorphic dyslalia; behavioral disorders \\
\hline & Ş.C. & female & 11 years & $\begin{array}{c}\text { M.M.D } \\
\text { psycho-behavioral immaturity }\end{array}$ \\
\hline & T.A. & female & 11 years & L.M.D; attention deficit \\
\hline
\end{tabular}

Table 2: Nominal table with subjects of control lot.

In the life of the child with MD, musical play fulfills the same role as work in adult life. Through music, play, exercise and good will, everything is easier to learn, especially if the exercises are accompanied by musical, motion, text, and song games, taking into account the particular structure of their personality. Thus, they easily resolve most of the intended goals in the instructive-educational curriculum of complex and integrated educational therapy (CIET), being motivated to experiment and learn new things (Table 2).

Dance is a way of expressing affective feelings and, therefore, a way of treating it. Equally, it is a way of communicating with the MD child to make him feel safe by diminishing anxiety. It is a procedure by which we help him to know his body better, to express his feelings and to free himself emotionally. By using a primary form of non-verbal communication, body expressing activities provide the MD's child with a way of interacting with the environment and with others when he is limited by a disability.

A basic principle of the program is the synthesis of the physical and relational aspects of the movement. It does not matter what skills are central, but the primordial focus is on developing relationship skills and social abilities. 
Under the influence of the activities of melotherapy and body expression algorithms for control of the tasks performed by the child are formed, such as:

- Stimulating the interest in knowing the environment, with its social relations; algorithms of intellectual activity are formed;

- Social skills that lead to psychosocial maturation;

- Correct, objective perception of one's own person;

- Accepting oneself and others;

- Educating affective balance, to ensure certainty in the manifestation of certain emotional impulses.

\section{Results and Discussion}

The therapeutic recovery and training program proposed and applied by its own methodology, characterized in particular by differentiated and individualized treatment of each pupil among those originally investigated, imposed a final assessment to highlight the results achieved. Both subjects in the experimental group and those in the control group were subjected to this assessment to see whether the assumptions of the research were confirmed or not. The experimental group benefited from a rehabilitative and formative program in occupational therapy activities, while the control group performed the educational therapy activity following the traditional methodological strategies included in the complex and integrated educational therapy (CIET).

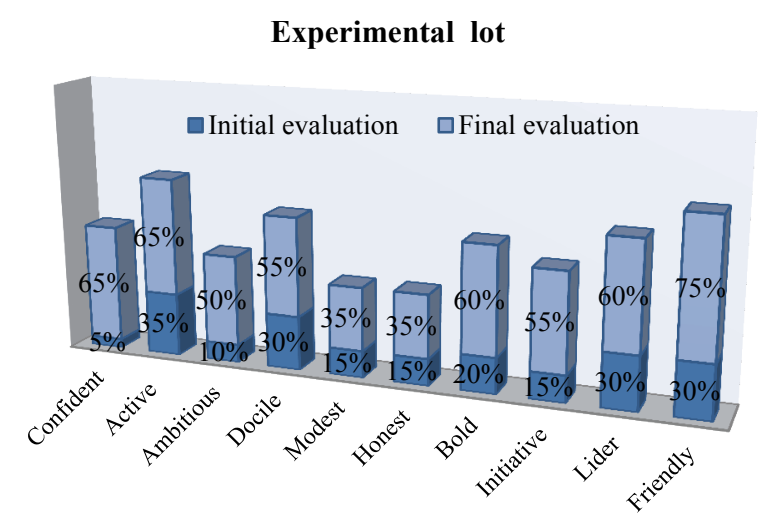

Figure 3: Questionnaire for establishing "child's profile in the extremes" comparative graph.

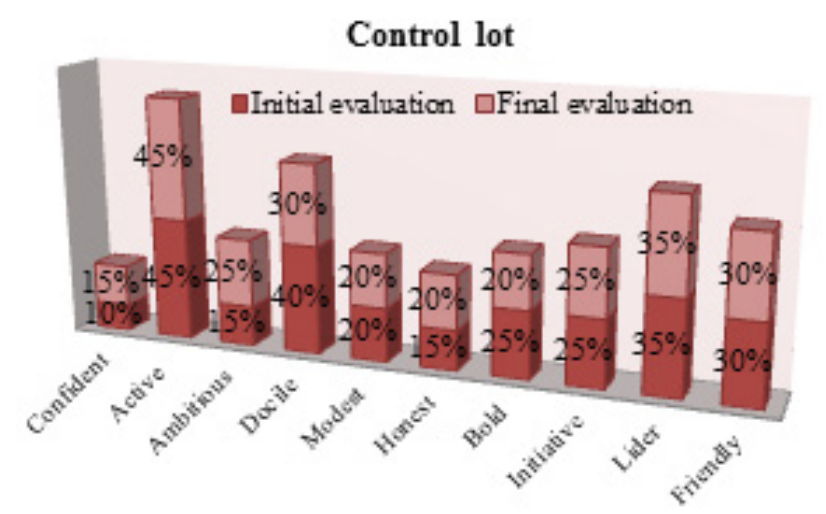

Figure 4: Questionnaire for establishing "child's profile in the extremes" comparative graph.
Sience the space of this study does not permit a detailed description of each step, we will refer just to the aspects of the research that highlights the purpose and objectives of the fund's research, namely, verifying the supposition that through melotherapy and body expression activities, in a relaxing, non-formal setting, one can change the attitude of the students from the experimental group towards themselves and others, as well as the socio-rectal behavior and motor skills. In terms of emotional development, even if it requires additional effort, the results of the final evaluation report reveal that the application of the intervention program to the students in the experimental group has contributed to the reduction of behavioral and emotional disorders, including the reduction of anxiety.

The final evaluation of the teaching staff highlighted the significant improvement of teachers' attitudes towards the student-teacher relationship, as regards the subjects of the experimental group. Due to the direct involvement and educational support of the pupils, the teachers have noted a qualitative improvement in the behavior of the pupils in this group, their attitudes towards school, colleagues, and adults; students have gained more confidence in what they do and implicitly in themselves. Regarding subjects in the control group, they stagnated at baseline or even regressed.

To confirm the previous statements, we will present the comparative analysis of the results obtained in some samples from the final evaluation by the experimental group and the control group, respectively.

The Interpretation of Teacher Questionnaire Results on Establishing the "Child's Profile in the Extreme" highlighted the fact that the teacher's perception of children is much more favorable (teachers have chosen the variants of response that are closer to the positive end of the pairs opposing personality traits) (Figure 3).

We find that in repeating the sample, the students in the experimental group who participated in the recuperative-formative program are perceived by their teachers as more confident in themselves (65\%), the most active and responsive (65\%), the more modest (35\%), the more active and receptive (65\%), the students in the experimental group who have participated in the recuperative-formative program, ), more daring (60\%) and more friendly (75\%). In the final assessment, the assessments made by the teachers on the pupils in the control group do not differ statistically significantly from those of the initial testing. Their perception does not change. Students in the control group complain more often of fatigue, are disappointed with their inability to compete

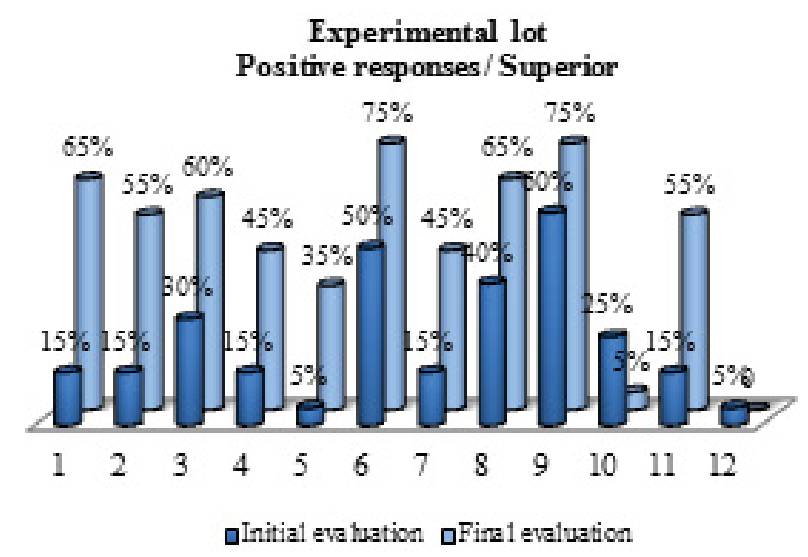

Figure 5: Frequency of positive responses to the affective maturity test. 


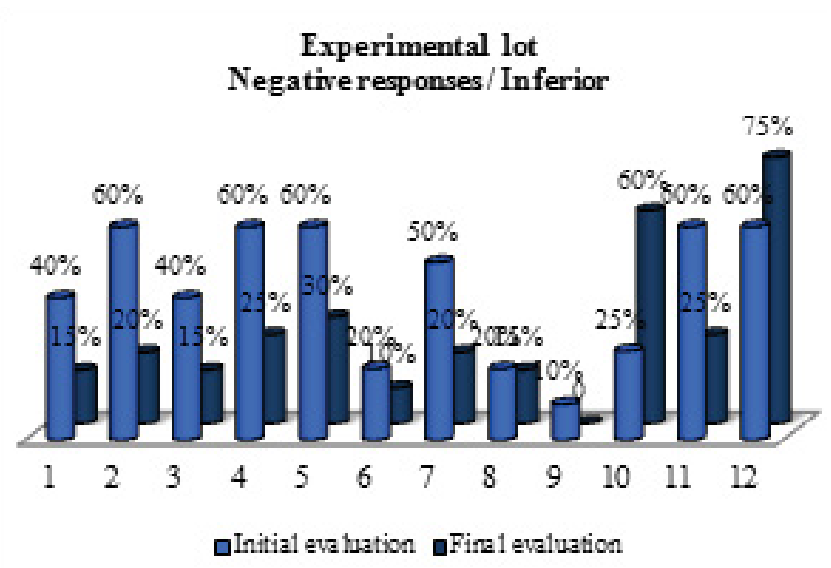

Figure 6: Frequency of negative responses to the affective maturity test.

\section{Control lot \\ Positive responses/Superior}

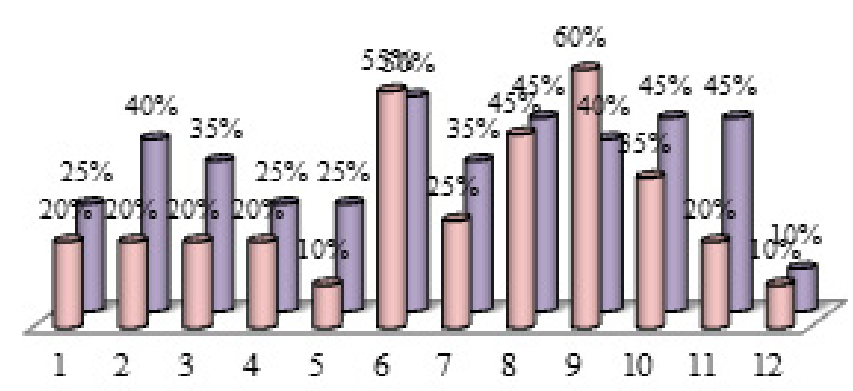

aInitial eva hation aFinal evaluation

Figure 7: Frequency of positive responses to the affective maturity test.

\section{Control lot
Negative responses/ Inferior}

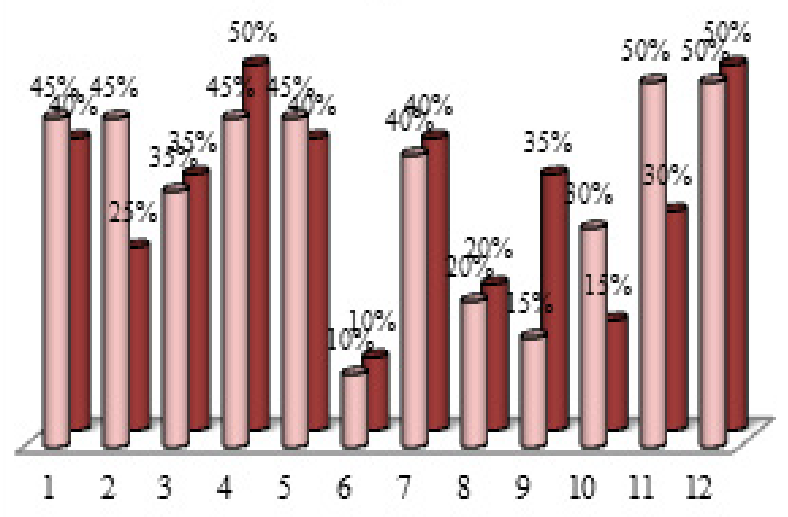

口Initial evahation $\square$ Firal evaluation

Figure 8: Frequency of negative responses to the affective maturity test.

with others, more often show a tendency to avoid all human activities that involve initiative and competition (Figure 4).
It can be stated that the results of the pupils in the experimental group at the final evaluation of the questionnaire on the "Child's Profile in the Extremes" are significantly higher than those of the pupils in the control group. Therefore, according to the teachers' assessment, the recovery and training program has contributed both to changing the attitudes of the students in the experimental group towards themselves and to others (confident, daring) as well as socio-affective behavior (friendly, less documented, more ambitious).

To validate the first research hypothesis, we checked whether the same program influenced the MD self-esteem. We found the students in the experimental group a more obvious tendency to appreciate appropriately / correctly in the affective maturity test.

From the comparative analysis of the data obtained after applying the affective maturity test in the two periods (test and retest), we can state that self-esteem and self-confidence of pupils of low school age with MD in the experimental group increased and those of children with MD in the control group is still influenced by the particularities of the educational model they are involved in (Figures 5 and 6).

The students in the control group have poor results, significantly lower than those of the experimental group. In most of the children in the control group, we can see a deficiency in behavioral regulation, adherence to rules in the absence of adult control, which leads to addiction and mismanagement. These children are characterized by advanced excitement and fatigue. If, under normal conditions of normal analyzer development and functioning, the dependence of other cognitive sensations can go unnoticed, in special blocking situations, diminishing sensory channels, the quality of cognitive processes depends to a large extent on the quality of the educational environment. The slow pace of development has multiple causes, the primordial being sensory deprivation (Figures 7 and 8).

Students in the control group have poor results, significantly lower than those of the experimental group. In most of the children in the control group, we can see a deficiency in behavioral regulation, adherence to rules in the absence of adult control, which leads to addiction and mismanagement.

In other words, the specific particularities of the social-affective development of children with MD of pre-school age, require for a special structure of education for forming and development, which should be centered on aspects that depend on children socialization. One of the conditions for this structure is to give the child with mental disability attention, love and affection, acceptance and recognition, encouragement and motivation. He often time, the child does not receive them in his family, and under these circumstances, an inadequate behavior promoted by an educator can influence in a negative way and quite easily the live of these children.

According to the opinion of some Romanian researchers, at children with MD of pre-school age, the dependence on the adult's opinion is quite high, what determines the acute need for its appreciation [1]. Always, students will appreciate the teacher who approaches them, who can motivate them through encourages, who appreciates and rewards each for his work and who always asks them what are the problems they are facing, trying to find a solution to eliminate any obstacle in their path.

We can concluded that the analysis and interpretation of the results got by MD students from the two lots, at the final evaluations, justifies us to support the confirmation of the two research assumptions.

\section{Conclusion}

In the case of special schools, the first steps of learning are decisive, 
Citation: Osiceanu ME, Zaharescu Ş (2017) Occupational Therapy's Role in Recovery of Children with Mental Disabillities. Clin Exp Psychol 3: 167. doi: 10.4172/2471-2701.1000167

Page 8 of 8

because each child with mental disabilities comes with his own way of psychological organization, but also with great emotional insecurity. It is considered that well-being, good mood, feelings of satisfaction are a decisive part in achieving success at the onset of schooling, in raising self-esteem and self-confidence, as well as in diminishing behavioral disorders.

The reduced volume of vocabulary (quantitative and qualitative), reduced capacity for free speech, reduced emotional tone, behavioral disturbances disturbs educational and therapeutical approach and does not allow for spectacular results or changes. That is why we adapted the methods to the real possibilities of each child and introduced into the educational, therapeutical, rehabilitative and formative activities, attractive elements that would make them cooperate in order to achieve progress.

The research in the field of occupational therapy remains extremely difficult and delicate. As Katrina Bannigan emphasized: „it appears that the research-practice gap exists for occupational therapists because they perceive and/or experience barriers to research utilisation. Research utilisation involves the application of the findings of research to practice. A barrier to research utilisation is anything that interferes with research utilisation, or is perceived as an interference. The range of barriers perceived and/or experienced by occupational therapists suggests that research utilisation is a complex problem. For example, therapists find that there is insufficient time to implement new ideas, no time to read research, statistical analyses are not understandable, literature is not compiled in one place, literature reports conflicting results and it is not easy to transfer findings into daily practice" [10].

Despite this difficulty, through this work, we advocate the importance of Occupational Therapies (OT) through melotherapy and body expression activities, development of the personality of the deficient children, improvement of image and self-esteem, perceptivemotor development, aesthetic taste, etc. At second level, we try to encourage teachers to use instead of the traditional methods provided in the CIET curriculum, non-formal educational and therapeutic strategies that can be used successfully for children with mild and medium mental deficiencies.

In the context of OT activities, the child can express himself freely. The more attractive activities, the more diversified the techniques, the more the child works with pleasure, the more he satisfies his curiosity and the need for knowledge, and the results are in line with expectations.

Using melotherapy and body expression activities as main activities, socio-emotional education and stimulation can be accomplished in a pleasant way, because a mentally deficient child learns more easily when stimuli are presented to his or her level of learning. It is possible to use games loved by children, namely: loved songs, musical games, text games, learning dance steps, roles in cultural and artistic activities, etc.
Melotherapy is the most effective form of socializing and recovery for mentally deficient children. Through melotherapy, the child with disabilities can explore the world around him, he can expand his sphere of skills, abilities, habits, shape his behavior, and from where he is the trainer. Thus, differences and barriers between children disappear, children with special educational needs can obtain small but motivated successes, which satisfies their need to be appreciated and integrated into society. The "thought" organization of the forms of achievement of the melotherapy, the pedagogical tact of the teacher/teacher-educator (in order to create a child with special educational needs a state of wellbeing and a positive attitude towards oneself), facilitates the process of integration of children with disabilities in educational institutions. For example, in the case of our research, during the course of the recuperative-formative program, we found that due to the melotherapy the timidity and the insecurity in execution gradually disappeared, the children became more active and more confident in their possibilities, and the emotional-affctivate behavior is considerably diminishing.

That is the reason why we finally recommend including musical games and specific body expressing activities in the therapeutic program for developing self-esteem, self-confidence, applying personalized intervention programs to mentally disabled children, encouraging their permanent appreciation too.

\section{References}

1. Gherghuţ A (2007) Sinteze de psihopedagogie specială. Ghid pentru concursuri şi examene de obţinere a gradelor didactice.

2. WHO (2001) International Classification of Functioning, Disabilities and Health - ICF, Geneva.

3. Păunescu C (1999) Terapia educaţională a persoanelor cu disfuncţii intelective.

4. Wilson EB (1998) Occupational Therapy for Children with Special Needs. Whurr Publishers Ltd, London.

5. Yalon-Chamovitz S, Selanikyo E, Artzi N, Prigal Y, Fishman R (2010) Occupational Therapy and Intellectual and Developmental Disability Throughout the Life Cycle. The Israeli Journal of Occupational Therapy 19: E3-E8.

6. Verza E (1998) Psihopedagogie specială. Bucureşti, E.D.P.

7. Popovici DV (2000) Introducere în terapia ocupaţională. Bucureşti, Ed. ProHumanitate.

8. Popovici DV, Niculcea D (1997) Meloterapia, in Terapia educaţională integrată Bucureşti, Ed. Pro-Humanitate.

9. American Occupational Therapy Association (2014) Occupational Therapy Practice Framework: Domain and Process. American Journal of Occupationa Therapy 68: S1-S48.

10. Bannigan K (2007) Making sense of research utilisation in Creek.

11. Long C, Cronin-Davis J (2006) Occupational Therapy Evidence in Practice for Mental Health. Oxford, Blackwell Publishing Ltd.

12. McKay EA, Craik C, Lim KH, Richards G (2008) Advancing Occupational Therapy in Mental Health Practice. Oxford, Blackwell Publishing Ltd.

13. Popescu A (1986) Terapia ocupaţională şi ergoterapia. Bucureşti, Ed. Medicală 